\title{
Fetus in fetu: two case reports from North African country
}

\author{
Moutaz Ragab ${ }^{1 *}$ (D), Omar Nagy Abdelhakeem², Omar Mansour ${ }^{1}$ (D), Mai Gad ${ }^{3}$ and Hesham Anwar Hussein ${ }^{4}$ (D)
}

\begin{abstract}
Background: Fetus in fetu is a rare congenital anomaly. The exact etiology is unclear; one of the mostly accepted theories is the occurrence of an embryological insult occurring in a diamniotic monochorionic twin leading to asymmetrical division of the blastocyst mass. Commonly, they present in the infancy with clinical picture related to their mass effect. About $80 \%$ of cases are in the abdomen retroperitoneally.

Case presentation: We present two cases of this rare condition. The first case was for a 10-year-old girl that presented with anemia and abdominal mass, while the second case was for a 4-month-old boy that was diagnosed antenatally by ultrasound. Both cases had vertebrae, recognizable fetal organs, and skin coverage. Both had a distinct sac. The second case had a vascular connection with the host arising from the superior mesenteric artery. Both cases were intra-abdominal and showed normal levels of alpha-fetoprotein. Histopathological examination revealed elements from the three germ layers without any evidence of immature cells ruling out teratoma as a differential diagnosis.

Conclusions: Owing to its rarity, fetus in fetu requires a high degree of suspicion and meticulous surgical techniques to avoid either injury of the adjacent vital structures or bleeding from the main blood supply connection to the host. It should be differentiated from mature teratoma.
\end{abstract}

Keywords: Fetus in fetu, Teratoma, Abdominal mass, Retroperitoneal

\section{Background}

Fetus in fetu (FIF) is a rare congenital anomaly resulting from anomalous embryogenesis in diamniotic monochorionic twin pregnancy [1]. Johann Friedrich Meckel, a German anatomist, was the first one to describe this condition in the 1800s, and so far, fewer than 200 cases are reported in literature [2].

The exact etiology is unclear. One of the mostly accepted theories is the occurrence of an embryological insult occurring in diamniotic monochorionic twins, leading to unsymmetrical division of the blastocyst mass, ending in a smaller cell mass engulfed within a mature sister embryo [3]. Further growth of the parasitic twin is

\footnotetext{
* Correspondence: moutaz.ragab@kasralainy.edu.eg

'Department of Pediatric Surgery, Cairo University Specialized Pediatric Hospital, Cairo, Egypt

Full list of author information is available at the end of the article
}

then arrested due to diminished blood supply or possibly underlying genetic defects [4].

Commonly, they present in the infancy with a clinical picture related to their mass effect; however, the oldest case in the literature is for a 47-year-old male. There is a slight male predominance [3]. About $80 \%$ of cases are located in the abdomen, retroperitoneally. Other less common sites include the head, sacrum, scrotum, and the chest [5].

Based on zygosity, FIF and teratomas could be differentiated by comparing normal and teratomatous tissue by applying cytogenic and isoenzyme electrophoretic techniques, which demonstrated that teratomas are always homozygous, while normal tissues are heterozygous for chromosomal polymorphisms at or near the centromere. This leads to a conclusion that mature cystic teratomas arise from a single germ cell that has completed the first meiotic division, but FIF is genetically identical to its host [6].

\section{Springer Open}

(c) The Author(s). 2021 Open Access This article is licensed under a Creative Commons Attribution 4.0 International License, which permits use, sharing, adaptation, distribution and reproduction in any medium or format, as long as you give appropriate credit to the original author(s) and the source, provide a link to the Creative Commons licence, and indicate if changes were made. The images or other third party material in this article are included in the article's Creative Commons licence, unless indicated otherwise in a credit line to the material. If material is not included in the article's Creative Commons licence and your intended use is not permitted by statutory regulation or exceeds the permitted use, you will need to obtain permission directly from the copyright holder. To view a copy of this licence, visit http://creativecommons.org/licenses/by/4.0/. 
Here, we present two cases of intra-abdominal FIF.

\section{Case presentation}

\section{Case 1}

A 10-year-old girl presented with fever for 3 months, generalized weakness, and abdominal pain. Clinical examination revealed a palpable hard tender mass in the central part of the abdomen, encroaching on the right hypochondrium. There was no organomegaly. The patient was not jaundiced.

Systematic evaluation and radiological studies were done. Laboratory results showed marked microcytic hypochromic anemia with hemoglobin level of $5.6 \mathrm{~g} / \mathrm{dL}$ and a total leukocytic count $9.9 \times 10 / \mu \mathrm{L}$. Serum albumin is $1.4 \mathrm{~g} / \mathrm{dL}$ and $\mathrm{LDH}$ is $189 \mathrm{U} / \mathrm{L}$. Other results were within the average of normal range. Tumor markers were also done with beta HCG less than 1 (reference range less than $5 \mathrm{mIU} / \mathrm{mL}$ ), alpha-fetoprotein $6.6 \mu \mathrm{g} / \mathrm{L}$ (reference range 0-20 $\mu \mathrm{g} / \mathrm{L}$ ), CEA 0.7 (reference range less than or equal to $3 \mathrm{ng} / \mathrm{mL}$ ), and CA-19 $9.2 \mathrm{U} / \mathrm{mL}$ (reference range is less than $37 \mathrm{U} / \mathrm{mL}$ ).

CT scans of the abdomen revealed a heterogeneous retroperitoneal mass about $30 \times 20 \times 15 \mathrm{~cm}$ extending in the right pararenal space up to the subhepatic region, showing a large cystic lesion with multiple areas of solid tissue component, fat attenuation, and calcifications, see Fig. 1.

Urgent surgical intervention was planned due to progressive increase in abdominal pain and tenderness. Exploratory laparotomy through a mid-line incision was done. A large well-encapsulated retroperitoneal mass about similar size that of seen on the CT scan was

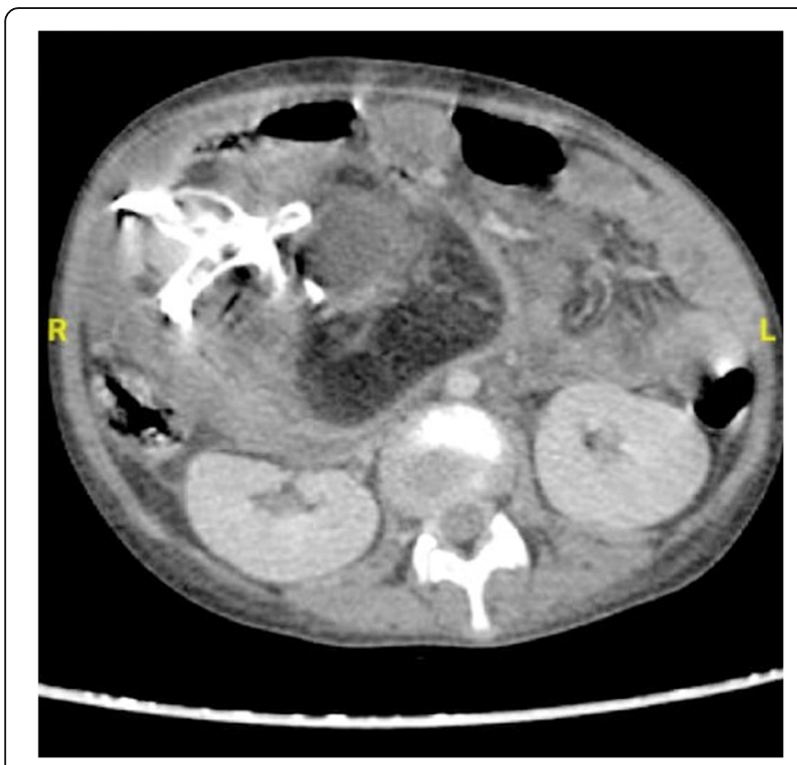

Fig. 1 CT scan of the retroperitoneal lesion showing solid and cystic components, fat attenuation, and calcification found, stretching the mesentery of the small intestine, and overriding and displacing the IVC and the aorta to the left side. The operation started with reflection of the mesentery of the right colon from anterior surface of the mass. The displaced IVC, aorta, and lower surface of the pancreas were meticulously dissected from the mass. The right renal vessels were dissected free off the mass, while preserving the right kidney and supra renal gland. The second part of the duodenum was markedly stretched and enlarged. The duodenum was transected transversally to enable retro-duodenal dissection and excision of the mass. The duodenum was repaired later and continuity restored. The mass was excised in two parts. Excision was complete with no residual parts. Few scattered retroperitoneal and mesenteric lymph nodes were found, and multiple biopsies were taken from them. Following precise hemostasis, intra-peritoneal drains were inserted. Closure of the abdomen was done (Fig. 2).

Postoperatively, the patient tolerated the procedure uneventfully with no remarkable complications.

Histopathological examination of the excised lesion showed a deformed embryo $(15 \times 14 \mathrm{~cm})$ with a head $(5$ $\times 5 \mathrm{~cm}$ ) with bony parts, 7 teeth, a deformed hand, and vertebral cartilaginous bodies. Cartilaginous and bony parts were partially covered with outer skin areas. There was a sac with fleshy hemorrhagic parts attached to the mass. Microscopically, there were elements from the 3 germ layers with no evidence of immature elements, confirming the diagnosis as a FIF (Fig. 3).

\section{Case 2}

A 4-month-old boy presented with a history of antenatal detection of an intraabdominal mass showing calcification and cystic areas on routine prenatal ultrasound at the 30th week of gestation. On clinical examination, there was a palpable hard mass in the right hypochondrium, reaching to the right iliac fossa, and no jaundice.

Postnatal multidetector computerized tomography (MDCT) showed a large well-defined intra-peritoneal lesion at the right hypochondrium measuring about $10 \times$ $7.5 \times 8 \mathrm{~cm}$, that showed mixed fat, soft tissue, and bones (vertebral bodies and long bones), suggesting the presence of fetal parts. All laboratory investigations and tumor markers (alpha-fetoprotein) were within normal limits for age (Fig. 4).

A decision was made to perform exploratory laparotomy through a right supra-umbilical transverse incision that revealed a mass about $10 \times 8 \mathrm{~cm}$ within the lesser sac, causing stretching of the duodenum. It was enclosed within a separate sac which was adherent to the aorta; meticulous dissection of the mass showed the presence of a vascular pedicle connecting it to the superior mesenteric artery just after the origin of the middle colic 


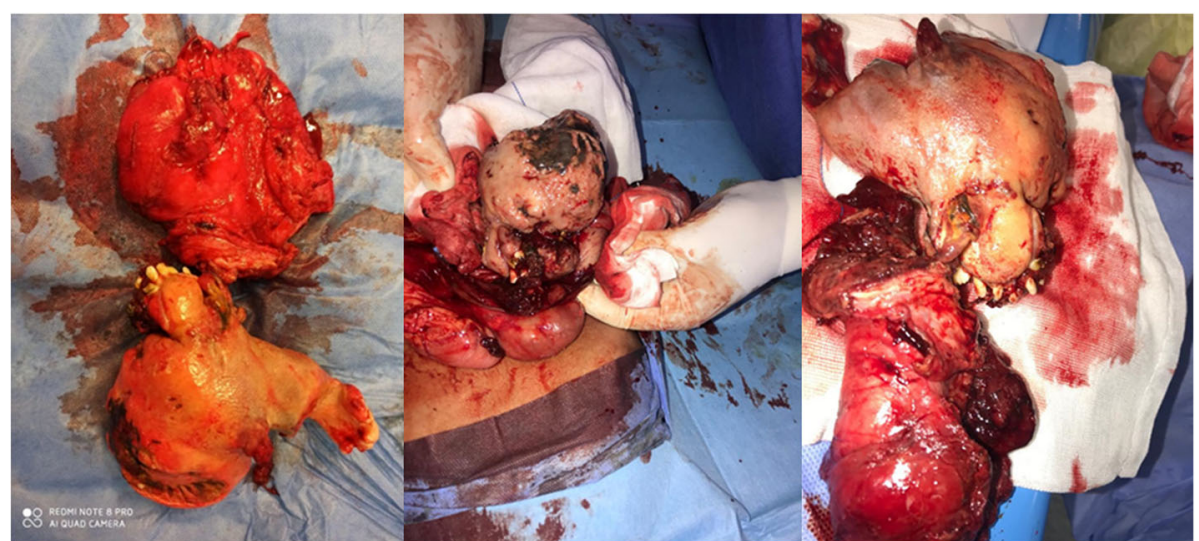

Fig. 2 Intra-operative view of the excised mass

artery. Ligation and division of the pedicle was done ensuring hemostasis; no enlarged lymph nodes were detected; closure of the abdomen in layers then was done (Fig. 5).

Postoperatively, the patient started oral feeding on the 2nd postoperative day and had an uneventful recovery.

Histopathological examination of this case also showed the presence of recognized fetal parts (upper and lower limbs), vertebral bodies, and being totally covered with skin. Microscopically, again, there were elements from the 3 germ layers with no evidence of immature elements (Fig. 6).

\section{Discussion}

With reported incidence of about 1 in 500,000 live births, fetus in fetu (FIF) stands as one of the extremely rare recorded anomalies. There is increased incidence in families with previous history of twin pregnancies. They are usually single and genetically identical to their host [3]. It is controversial whether to consider FIF as a highly differentiated teratoma or a distinctive pathology.

FIF is differentiated from a highly organized teratoma (with potential malignancy) prenatally by the presence of the spatially organized organs (anterior-posterior, cranio-caudal, and lateral/symmetrical development) depending on the vertebral bodies, which presence indicate that notochord stage of fetal development has been reached. Willis considered the presence of vertebral column as a mandatory differentiating point between FIF and fetiform teratoma [7]. Nevertheless, spatially organized and well-recognized organs such as limbs may favor the same fetal developmental stage.

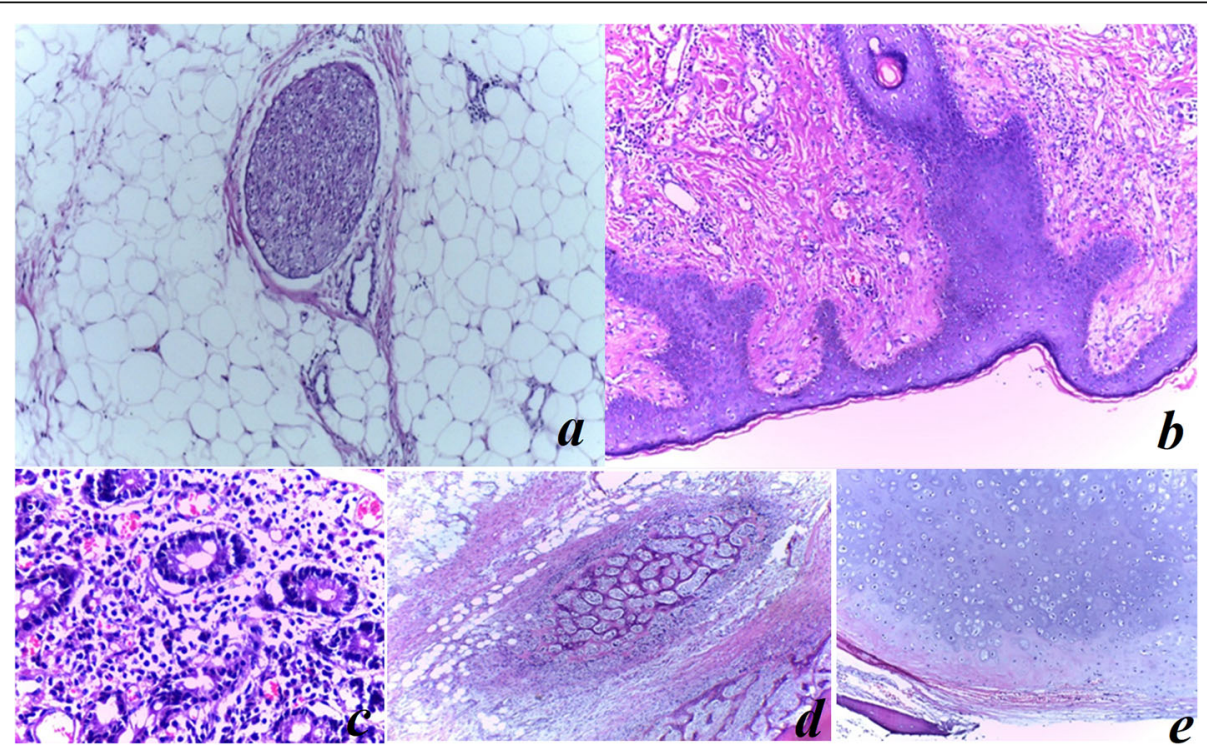

Fig. 3 Microscopic picture showing $\mathbf{a} \times 20 \mathrm{H} \& \mathrm{E}$ slide fat and nerve, $\mathbf{b} \times 20 \mathrm{H} \& \mathrm{E}$ slide of skin, $\mathbf{c} \times 40 \mathrm{H} \& \mathrm{E}$ slide of glandular epithelium, $\mathbf{d} \times 20$ H\&E slide of bone and fat, $\mathbf{e} \times 20 \mathrm{H} \& \mathrm{E}$ slide of mature cartilage and bone 


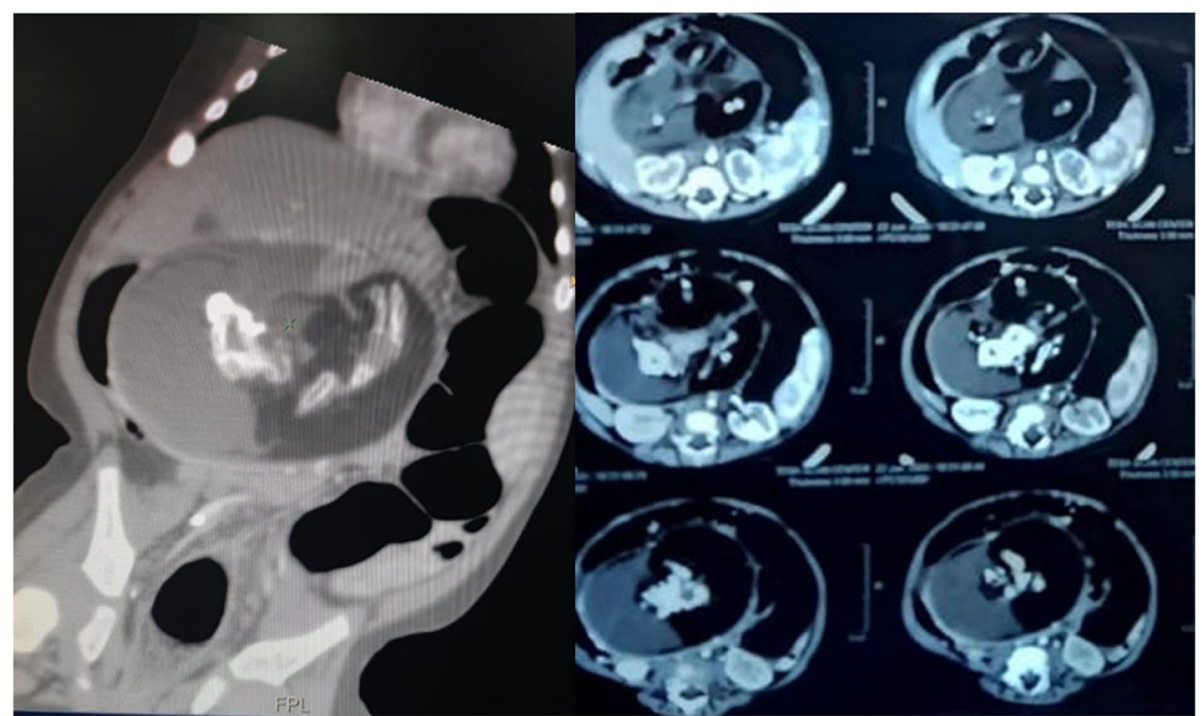

Fig. 4 MDCT showing mixed fat, soft tissue, and bones (vertebral bodies and long bones)

Moreover, each condition has a different genetic pattern supporting the hypothesis of distinct etiopathogenesis: FIF is genetically identical to its host; on the contrary, fetiform teratomas are homozygous [8]. Based on that, having a vertebral column will differentiate FIF from teratomas, yet it fails to do so with other spectrum of monozygotic twin pregnancies, such as conjoined parasitic twin, detached external twin, and embryonic vestigial inclusion.

FIF is derived from totipotent inner cell mass (which can give rise to both embryonic or extraembryonic cells), while teratomas arise from pluripotent cells without organogenesis or vertebral segmentation, both containing different tissues from one or more germinal cell layers [3]. Spencer sets criteria for a mass to earn the definition of FIF; one or more of the following characteristics must be achieved: having a separate sac, normal skin coverage either partially or completely, the presence of grossly recognizable anatomical parts, one or more vascular connections with its host [9].

The role of tumor markers is confined to the differentiation between FIF and other causes of intra-abdominal calcification, including teratoma, neuroblastoma, adrenal hemorrhage, meconium pseudocyst, and viral infection. The most used markers are $\beta$-human choriogonadotropin (hCG), AFP, and urine homovanillic acid [3].

Despite being a benign condition, and complete surgical excision is curative, the potential of malignancy should be kept in mind. Till now, there is only one case reported in literature with malignant transformation [10]. Follow-up with imaging and tumor markers is advised in cases showing immature components; teratomas require a longer and a closer follow-up [3].

Owing to mass effect, FIF may exhibit its symptoms by compressing the surrounding structures leading to abdominal distension, feeding difficulties, vomiting, jaundice,

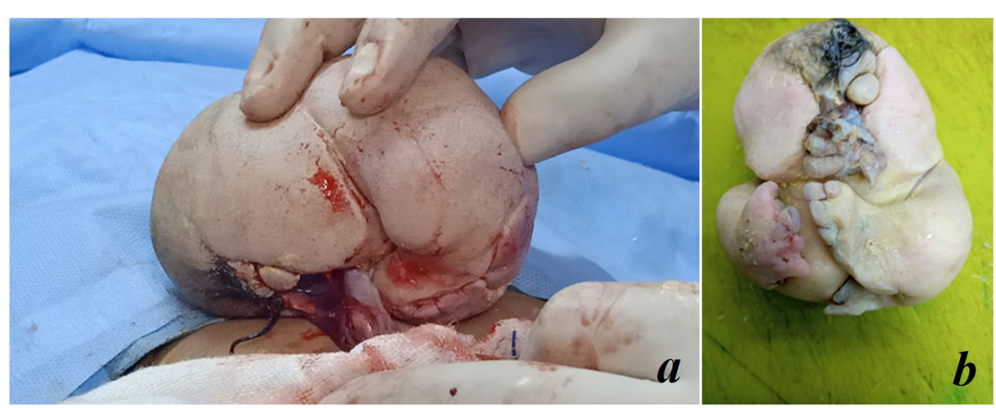

Fig. 5 a Intraoperative view showing the vascular pedicle. b Postoperative figure showing lower and upper limbs, and complete skin coverage of the mass 

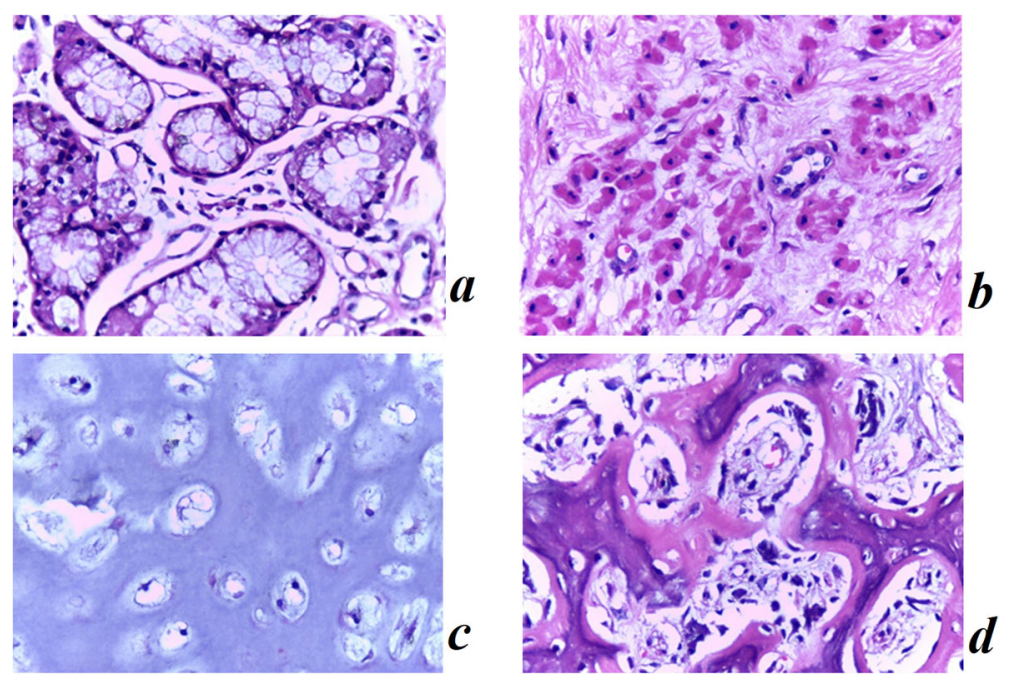

Fig. 6 a $\times 40$ H\&E slide of glandular epithelium with goblet cells. $\mathbf{b} \times 40$ H\&E slide skeletal muscles. $\mathbf{c} \times 40$ H\&E slide of mature cartilage. $\mathbf{d} \times 40$ H\&E slide of bone

renal function abnormalities, and respiratory distress [11]. It is worth mentioning that few numbers of cases were diagnosed antenatally by ultrasound; moreover, the sonographic features of FIF differ considerably [11].

In our first case, the main presentation was a palpable abdominal mass and anemia which could be nutritional because of feeding difficulties from the mass effect. In the histopathological examination, all the findings were in keeping with the diagnosis of fetus in fetu rather than retroperitoneal teratoma such as the presence of a sac, partial skin coverage, presence of hand, and there was no evidence of immature cells. Moreover, tumor markers were within the normal range for age.

In the second case, the diagnosis was made based on the antenatal ultrasound findings and the CT scan after birth, the mass was enclosed in a sac, and there was a single vascular connection with the host. Fetal parts were present, and histopathological examination showed no immature elements. Both cases in our report are likely to be FIF rather than a mature teratoma.

\section{Conclusion}

Owing to its rarity, FIF requires a high degree of suspicion and meticulous surgical techniques to avoid either injury of the adjacent vital structures or bleeding from the main blood supply connection to the host. FIF should be differentiated from teratoma, and although they are benign lesions, follow-up is advised.

\section{Abbreviations}

FIF: Fetus in fetu; HCG: Human chorionic gonadotropin;

CEA: Carcinoembryonic antigen; CA: Cancer antigen; MDCT: Multi detector computerized tomography; IVC: Inferior vena cava

Acknowledgements

Not applicable.

\section{Authors' contributions}

MR: drafting manuscript, literature search. OA: main operator of the second case, data interpretation, figures. OM: critical appraisal and revision of the manuscript. MG: histopathologist of both cases, data collection, high/power figures. HH: main operator of the first case, revision of the manuscript. All authors have read and approved the manuscript

\section{Funding}

No funding was received for this study.

\section{Availability of data and materials \\ Not applicable.}

\section{Ethics approval and consent to participate}

Ethical approval was obtained from tertiary-based university hospitals [Cairo University — Minia University] where both cases were operated upon, informed assent was obtained from the parents prior to any procedure, and counseling with the whole medical team was done. Committee's reference number is not applicable.

\section{Consent for publication}

Written informed consent for publication of patient information was provided by the guardians of both cases.

\section{Competing interests}

The authors declare no conflict of interest.

\section{Author details}

'Department of Pediatric Surgery, Cairo University Specialized Pediatric Hospital, Cairo, Egypt. '2Department of Pediatric Surgery, Minia University, Minia, Egypt. ${ }^{3}$ Department of Surgical Pathology, National Cancer Institute, Cairo University, Cairo, Egypt. ${ }^{4}$ Department of Surgical Oncology, National Cancer Institute, Cairo University, Cairo, Egypt.

Received: 4 August 2020 Accepted: 17 December 2020

Published online: 18 January 2021

\section{References}

1. Sharma A, Goyal A, Sharma S (2012) Fetus in fetu: A rare case report. J Res Med Sci Off J Isfahan Univ Med Sci 17(5):491

2. Issa MGME (2019). Fetus in fetu: A rare case of intra-abdominal mass. Radiol Case Rep 14(9):1171-1174. Published 2019. doi: https://doi.org/10.1016/j. radcr.2019.07.003.

3. Taher HMA, Abdellatif M, Wishahy AMK et al (2019) Fetus in Fetu: Lessons Learned from a Large Multicenter Cohort Study [published online ahead of 
print, 2019 Nov 26]. Eur J Pediatr Surg. https://doi.org/10.1055/s-00391698765

4. Tiwari C, Shah H, Kumbhar V, Sandlas G, Jayaswal S (2016) Fetus in Fetu: Two Cases and Literature Review. Dev Period Med 20(3):174-177

5. Barakat RMB, Garzon S, Laganà AS, Franchi M, Ghezzi F (2019). Fetus-in-fetu: a rare condition that requires common rules for its definition [published online ahead of print, 2019 Jun 7]. Arch Gynecol Obstet . doi:https://doi.org/ 10.1007/s00404-019-05211-y.

6. Jason R Weiss, Jeanette R Burgess, Keith J Kaplan. Fetiform teratoma (homunculus). Arch Pathol Lab Med. 2006;130(10):1552-1556.doi: https://doi. org/10.1043/1543-2165(2006)130[1552:FTH]2.0.CO;2

7. Willis RA (1962) The Borderland of Embryology and Pathology, 2nd edn. Butterworth \& Co Publishers Ltd, Washington, DC, pp 442-462

8. Traisrisilp K, Srisupundit K, Suwansirikul S et al (2018). Intracranial fetus-infetu with numerous fully developed organs. J Clin Ultrasound 46:487-493. https ://doi.org/https://doi.org/10.1002/jcu.22566.

9. Spencer R (2001) Parasitic conjoined twins: external, internal (fetuses in fetu and teratomas), and detached (acardiacs). Clin Anat 14(06):428-444

10. Keshava Murthy M, Hanumanthaiah AE et al (2014) Fetus in fetu: a case report and review of literature. JIMSA 27(01):26

11. Ruffo G, Di Meglio L, Di Meglio L, Sica C, Resta A, Cicatiello R (2018) Fetusin-fetu: two case reports. The Journal of Maternal-Fetal \& Neonatal Medicine. https://doi.org/10.1080/14767058.2018.1449207

\section{Publisher's Note}

Springer Nature remains neutral with regard to jurisdictional claims in published maps and institutional affiliations.

\section{Submit your manuscript to a SpringerOpen ${ }^{\circ}$ journal and benefit from:}

- Convenient online submission

- Rigorous peer review

- Open access: articles freely available online

High visibility within the field

- Retaining the copyright to your article

Submit your next manuscript at $\boldsymbol{\nabla}$ springeropen.com 